\title{
MANIFESTAÇÕES ESPORTIVAS NAS COMEMORAÇÕES DO CENTENÁRIO DA INDEPENDÊNCIA DO BRASIL (1822-1922) NO RIO GRANDE DO SUL
}

\author{
Paulo Renato Vicari \\ Universidade Federal do Rio Grande do Sul , Porto alegre, Rio Grande do Sul, \\ Brasil
}

\section{Carolina Fernandes da Silva}

Universidade Federal do Rio Grande do Sul , Porto alegre, Rio Grande do Sul, Brasil

\begin{abstract}
Resumo
Em 1922 o Brasil comemorou o centenário de sua independência, ano marcado por festejos em várias áreas, dentre elas a esportiva. Entre esses, estavam os Jogos Latino-Americanos, realizados no Rio de Janeiro. Porto Alegre também promoveu seu evento, os Jogos Olímpicos. O objetivo dessa pesquisa é reconstruir como sucederam esses jogos em Porto Alegre. Para tanto, realizou-se uma coleta de dados, especialmente em jornais. A análise revelou o reconhecimento do esporte como uma prática cultural privilegiada nestas festividades. Porto Alegre ocupou um papel de relevância nas comemorações, ao enviar atletas para os jogos do Rio de Janeiro e organizar seu próprio evento. Tal participação provavelmente resultou de sua forte tradição no associativismo esportivo.
\end{abstract}

Palavras chave: História do Esporte. Jogos Latino-Americanos. Jogos Olímpicos.

\section{Introdução}

O ano de 1922 é muito significativo para a história do Brasil, pois se distingue pelas comemorações do Centenário da Independência do país (1822-1922). Diversos eventos comemorativos ocorreram em diferentes domínios da sociedade brasileira, inclusive no campo esportivo. No Rio Grande do Sul várias cidades promoveram eventos esportivos com caráter comemorativo aos cem anos de independência do país, como os Jogos Olímpicos realizados na cidade de Porto Alegre, capital do Estado.

Além desses acontecimentos, atletas sul-rio-grandenses participaram de uma competição esportiva realizada no Rio de Janeiro, capital do país na 
época, e muito destacada pelos jornais, os Jogos Latino-americanos. Este evento constava em uma programação mais abrangente, denominada Programa da Exposição Internacional.

Possivelmente, por fazer parte de um grande e diversificado programa de comemorações, a competição recebeu diferentes denominações nas seguintes fontes impressas analisadas: jornal Correio do Povo; jornal A Federação e Relatório do Comitê Organizador dos Jogos. Desta forma, os jogos, já na sua denominação, foram envolvidos por diferentes representações, tais como: Jogos Regionais da América do Sul; Jogos da América do Sul; Jogos Latino-Americanos; Jogos Atléticos Latino-Americanos; e Jogos Olímpicos Latino-Americanos.

Assim, apesar de não haver uma denominação única, percebe-se que a disputa simbólica, em certo momento, visava abranger os países latinoamericanos. Desta maneira, para fins deste estudo, adotamos a denominação Jogos Latino-Americanos, em razão de ser a designação mais recorrente nas fontes históricas consultadas.

Além da cidade do Rio de Janeiro, provavelmente em outras cidades e Estados do país também foram promovidas festividades. No Estado do Rio Grande do Sul destaca-se o evento esportivo denominado Jogos Olímpicos, sediado na capital, Porto Alegre. Esse evento contou com a participação de diversos clubes sul-rio-grandenses nas competições. Diante dos acontecimentos esportivos referidos, a presente pesquisa apresenta como objetivo reconstruir como sucederam os Jogos Olímpicos em Porto Alegre no ano de 1922.

A narrativa histórica foi produzida com base em uma revisão bibliográfica, além de ter como fonte de consulta os dois jornais de maior circulação no Estado do Rio Grande do Sul no período demarcado para o estudo: Correio do Povo e A Federação. Esses periódicos, segundo a classificação de Rüdiger (1993), pertenceram a diferentes fases ou regimes jornalísticos do Estado. O Correio do Povo ${ }^{1}$ seguia os conceitos de jornalismo "informativo" e "indústria cultural", gerada no início do século XX, enquan-

1

Fundado 1895, ainda sob os ecos da Revolução federalista (18931895 ) orientou-se por uma linha neutra que o distanciasse dos dois extremos desta contenda: os federalistas maragatos, seguidores de Gaspar Silveira Martins e os seguidores do republicano Júlio de Castilhos, apelidados de Pica-paus.

Pensar a Prática, Goiânia, v. 17, n. 2, p. 485-502, jan./mar. 2014 486 
to que o jornal A Federação ${ }^{2}$ era conduzido pelo conceito de jornalismo "político-partidário", desde sua formação até a década de 1930. Ambos os tipos de jornalismo se entrelaçavam ao mesmo tempo em que se conflitavam.

Foram examinados todos os jornais publicados diariamente nos meses de Agosto, Setembro e Outubro do ano de 1922, com a intenção de buscar informações que antecederam e sucederam os eventos esportivos. A maioria das notícias referentes aos Jogos Latino-Americanos e aos Jogos Olímpicos do Rio Grande do Sul foi localizada no mês de Setembro, já que a data da Independência do Brasil é comemorada no dia sete desse mês. Esse período geralmente é denominado "Semana da Pátria", e é marcado por comemorações realizadas na capital do Rio Grande do Sul, no interior do Estado, bem como em todo o Brasil.

Determinados jornais do interior do Estado do Rio Grande do Sul, como "O Templário", de Pelotas; "O Boato" e "O Carteiro", de Bagé; "O Santamarienhense" e "Diário do Interior", de Santa Maria, foram consultados. No entanto, nesses exemplares não havia registro de eventos esportivos em comemoração ao Centenário da Independência do Brasil. Este estudo ainda utilizou de artigos, sites oficiais, livros e atlas do esporte para a revisão bibliográfica da pesquisa. Cabe salientar que após 90 anos das comemorações do centenário, completados em 2012, foi publicado o livro intitulado "Jogos Olímpicos Latino-Americanos - Rio de Janeiro 1922" (TORRES, 2012), patrocinado pela Confederação Brasileira de Atletismo (CBAt).

Tal obra comemorativa (TORRES, 2012), publicada no século XXI, denota o interesse em atualizar a memória esportiva do país, bem como também retoma representações de uma identidade nacional, produzidas por conta de tais comemorações. Como afirma Ortiz (1994), no Brasil, a identidade nacional é abstrata, desta forma, existente no mundo das ideias por meio de representações como a identidade cultural. Para Assmann (1995) a identidade cultural está relacionada a grupos que concebem a sua unidade e peculiaridade através de uma imagem comum do seu passado.

Nesta perspectiva, no caso deste estudo, os eventos esportivos comemorativos do Centenário da Independência do Brasil se constituíram em espaço social de negociação de representações de uma identidade cultural brasileira, reconstruindo e preservando um passado comum aos brasileiros.

Fundado em 1884, tornou-se porta-voz de um ideário republicano e da ideologia positivista de Augusto Comte, adaptada por Júlio de Castilhos à realidade da Província do Rio Grande do Sul, naquilo que mais tarde ficou conhecido como "castilhismo", sendo o modelo do jornalismo político-partidário vigente no Rio Grande do Sul até o Estado Novo.

Pensar a Prática, Goiânia, v. 17, n. 2, p. 485-502, jan./mar. 2014 487 
Tendo em vista que este se trata de um estudo de memória, partimos do entendimento de que a realidade é construída pelo processo de memória. Desta forma, as informações foram interpretadas com base no conceito de Burke (1992), que trata da memória como principal responsável por instituir uma referência histórica comum sobre a origem e a formação de grupos étnicos. O referido autor sistematizou possíveis formas de transmissão da memória, a saber: tradições orais; memórias escritas; memórias das imagens; o espaço (físico ou imaginário); as ações sociais e repetitivas (referente aos rituais, cerimônias e técnicas corporais).

Para Assmann (1995), a memória cultural inclui corpos de textos reutilizáveis, imagens e ritos específicos de cada sociedade em cada época, cujo cultivo serve para estabilizar e transportar a autoimagem desta sociedade.

Este estudo focaliza na transmissão da memória alusiva às ações sociais e repetitivas (BURKE, 1992), no caso, as comemorações esportivas do Centenário da Independência. Schemes (2005) afirma que as festas esportivas são uma das formas mais características de propaganda política, atuando no sentido de despertar o sentimento nacionalista nas pessoas, além de desenvolverem representações de identidades culturais brasileiras, por meio de símbolos. Ambos os jogos, tanto no Rio de Janeiro, quanto o realizado no Rio Grande do Sul tinham como finalidade afirmar uma ideia de um "novo Brasil", por meio da reconstrução da memória.

Conforme Assmann (1995), a capacidade de reconstruir está conectada com a concreção da identidade. Esta trabalha pela reconstrução da memória cultural, ou seja, ela sempre relaciona o conhecimento para uma situação contemporânea, é fixada em figuras imóveis de memória e em estoque de conhecimento.

Nessa direção, os esportes podem ser vistos como uma das práticas culturais que, por meio dos eventos comemorativos de 1922, contribuiu para a reconstrução da memória nacional brasileira. Os eventos eram o anúncio de um novo momento do país, que consolidava sua independência e que pisava firme na direção da construção de uma identidade cultural.

\section{A representação do Rio Grande do Sul nos Jogos Latino-Americanos}

A realização dos Jogos Latino-Americanos assinalou uma data oficial no calendário nacional, em um período de mudanças em vários setores da sociedade brasileira: fundação do Partido Comunista Brasileiro; realização da Semana de Arte Moderna; início da marcha da Coluna Prestes; eleição do novo presidente do país sob Estado de Sítio. Mesmo com essas mudanças políticas, o esporte emergiu como uma prática cultural que foi privilegiada

Pensar a Prática, Goiânia, v. 17, n. 2, p. 485-502, jan./mar. 2014 488 
no Programa da Exposição Internacional, por meio da organização dos Jogos Latino-Americanos.

Depois da filiação na Confederação Sul-Americana, o Brasil, visando às comemorações de seu Centenário de Independência, candidatou-se para sediar o III Sul-Americano de Atletismo. Inicialmente, este evento estava programado para ser realizado na Argentina. Somente após a confirmação da competição no Brasil, a comissão organizadora dos festejos do Centenário foi analisar os locais e como organizaria os jogos. Esta postura certamente contribuiu para críticas que surgiram quanto à organização e condições para os atletas. O III Sul-Americano de Atletismo, da mesma forma que o V Sul-Americano de Futebol, foi incluído nos Jogos Latino-Americanos.

A proposta dos Jogos, uma das primeiras nesta parte do continente, reuniria no mesmo evento e cidade vários esportes como futebol, basquetebol, tênis, natação, esgrima, tiro, remo, boxe, hipismo, além das variadas provas de atletismo, como salto em distância, em altura, salto com vara e as corridas de curta, média e longa distância, incluindo a maratona, cujo percurso chegaria a 42 quilômetros. As provas aconteceriam simultaneamente ao longo dos meses de Setembro e Outubro.

Para dar ainda mais credibilidade e caráter oficial à competição esportiva, as Forças Armadas Brasileiras tiveram forte atuação em sua realização. A organização do evento ficou a cargo da Comissão Organizadora dos Festejos Desportivos do Centenário, presidida pelo coronel Estellita Werner, também presidente da Liga de Sports do Exército (LSE). O Comitê Olímpico Internacional (COI) escolheu mais um parceiro para a organização dos jogos: a Associação Cristã de Moços (ACM). O consórcio COI-ACM desejava o reconhecimento oficial do evento por parte do COI, sendo este o primeiro dos jogos regionais com previsão de realização periódica em todo o mundo. Isto mostra a importância dos jogos no Brasil.

Fatores entusiasmaram as competições esportivas no Centenário, como o cosmopolitismo da Bélle Époque, marcado pela preocupação de se estabelecer uma comparação do Brasil com as demais nações do mundo. Outro fator foi o modernismo, que buscava definir de maneira mais autêntica o povo brasileiro. Desta forma, o projeto dos Jogos Latino-Americanos tinha como intuito revelar ao mundo um novo modelo de nação. Um acontecimento durante esses festejos que pode exemplificar esse contexto foi a demonstração de natação de Violeta Coelho Neto, considerada a primeira mulher brasileira a nadar em público, segundo Lenk (1986). O ato aconteceu no "Tanque natatório" da Urca.

Quanto à cerimônia de abertura dos Jogos Latino-Americanos, ela aconteceu no estádio do Fluminense Football Club, local da maioria das

Pensar a Prática, Goiânia, v. 17, n. 2, p. 485-502, jan./mar. 2014 489 
competições. Entre os outros locais de competição estava a piscina construída pelo Governo Federal na Praia Vermelha do Rio de Janeiro, inaugurada em 1922, especialmente para os jogos em comemoração ao Centenário (AMARO JUNIOR, 1947).

Cabe destacar a relevância do Fluminense Football Club na organização dos jogos. O clube contou com ajuda do governo somente na reconstrução do seu estádio - o qual foi ampliado para receber 25.000 espectadores - e arcou com todos os outros gastos, além de ceder instalações e apoio logístico. Esse feito foi reconhecido pelo Comitê Olímpico Internacional (COI) que premiou o clube em 1949 com a Taça Olímpica, que é o mais cobiçado troféu do esporte mundial. Também chamado de Taça de Honra, tem como finalidade reconhecer anualmente aquele que, no juízo do COI, mais fez em prol do olimpismo e do esporte.

A confirmação da realização dos Jogos Latino-Americanos foi demorada e resultou de muitas reuniões entre o governo brasileiro, o $\mathrm{COI}$ e a ACM. O COI indicou o Conde belga Henri de Baillet-Latour, o então VicePresidente da organização, como o seu representante oficial junto ao evento.

A abertura solene dos jogos aconteceu no dia 13 de Setembro de 1922, apesar de, no dia sete de Setembro, ter ocorrido uma grande parada (desfile) esportiva nos moldes da parada militar. Neste desfile, os militares imprimiram sua participação com representações dos Jogos do Centenário da Independência, como os aparatos utilizados para as práticas esportivas, além de estarem devidamente fardados com uniforme de gala, contribuindo para a distinção do evento.

A programação dos festejos do Centenário da Independência, conforme Torres (2006), não foi uma tarefa fácil de descobrir. Sabe-se que foram realizados três eventos esportivos distintos: Jogos Latino-Americanos; Jogos Militares Internacionais; e os Campeonatos Esportivos Internacionais. No relatório do Comitê Organizador constam sob o título "Jogos Atléticos Latino-Americanos" os resultados das competições dos seguintes esportes: atletismo, basquetebol, boxe, remo, saltos ornamentais, esgrima, futebol, hipismo, natação, polo aquático, tênis e tiro. Esta listagem indica as possíveis práticas esportivas que compunham o evento, disputadas por participantes de países latino-americanos.

Em um primeiro momento, estava previsto estender o convite de participação nas festividades comemorativas do Centenário da Independência a Cuba, México e Porto Rico. Todavia, uma grave crise econômica no Brasil levou o governo brasileiro a declinar do convite a estas nações. Esta foi a justificativa dada pelo governo, que afirmou, inicialmente, que os jogos se limitariam ao âmbito nacional. Apesar disso, os seguintes países enviaram delegações ao Rio de Janeiro: Argentina, Chile, Uruguai, e Paraguai. Possi-

Pensar a Prática, Goiânia, v. 17, n. 2, p. 485-502, jan./mar. 2014 490 
velmente, este foi o motivo de a competição obter diferentes denominações, por, em um primeiro momento, desejar abranger a América Latina e, posteriormente, se resignar aos países da América do Sul.

Entretanto, percebeu-se que a participação da delegação do Paraguai não foi mencionada em algumas fontes. Segundo dados da ACM, foram inscritos 1.200 participantes nos três eventos dos Jogos do Centenário da Independência (Jogos Latino-Americanos, Jogos Militares Internacionais e os Campeonatos Esportivos Internacionais). Deste total de participantes, 500 atletas disputaram, exclusivamente, os Jogos Latino-Americanos, evento que aconteceu no período de 27 de Agosto a 15 de Outubro de 1922. O interesse despertado pelos eventos esportivos do Centenário pode ser comprovado pelo número significativo de espectadores, cerca de 162.000 pessoas, conforme aponta o Atlas do Esporte no Brasil.

Nos Jogos Latino-Americanos evidenciou-se a presença de atletas sul-rio-grandenses na delegação brasileira, os quais conquistaram vaga em razão da participação destacada no campeonato nacional, que selecionou os três melhores em cada competição para representar o Brasil. Dos sete sulrio-grandenses que foram disputar o Campeonato Nacional, seis foram selecionados para representar a equipe brasileira nos Jogos Latino-Americanos: Willy Seewald, primeiro lugar no arremesso de dardo; Willy Fick, primeiro lugar no salto em altura; Emílio Titzmann, terceiro lugar no salto em altura; Oscar Wolf, terceiro lugar na corrida de 100 metros; Oswaldo Brucke, terceiro lugar na corrida de 800 metros; e Alvaro Ferreira de Souza - conhecido como "Baianinho". Ele ficou em quarto lugar na prova de corrida de 10.000 metros, porém, mesmo assim, foi convocado para completar a delegação brasileira, na condição de reserva. O único competidor sul-rio-grandense que não alcançou a classificação, e por isso não fez parte da delegação brasileira nos Jogos Latino-Americanos, foi Alfredo Doernte, que estava como substituto do atleta Herzog na seletiva nacional da prova de lançamento de disco.

No Campeonato Nacional, que serviu de seletiva para constituir a representação brasileira nos Jogos Latino-Americanos, participaram 46 atletas de São Paulo, 23 atletas do Rio de Janeiro, 18 atletas da Liga da Marinha, e sete atletas do Rio Grande do Sul. Embora com um número reduzido de atletas, o Rio Grande do Sul venceu em pontos a Liga da Marinha. A imprensa na época comentou a ausência de diversos recordistas sul-rio-grandenses na seletiva nacional, como por exemplo, os atletas Frederico Behrends (corrida 100 metros), Jorge Py (salto em distância), Argelino Gomes (corrida 400 metros) e Arno Ely (corrida 1500 metros).

Quanto ao desempenho dos sul-rio-grandenses nos Jogos LatinoAmericanos, cabe destacar, segundo Mazo e col. (2012), a grande vitória de 
Willy Seewald, que arremessou o dardo a 56,885 metros $^{3}$, superando o recorde sul-americano e deixando o até então recordista sul-americano, Arturo Medina, do Chile, na segunda colocação. Outro destaque foi Willy Fick, no salto com vara, que suplantou o seu próprio recorde brasileiro, saltando 3,30 metros ${ }^{4}$.

A respeito do atleta sul-rio-grandense Sebastião Wolf, que esteve presente nos Jogos Olímpicos de 1920, na Antuérpia, há dúvidas a respeito de sua participação nos Jogos Latino-Americanos, pois como era militar, seus resultados podem ter acontecido nos Jogos Militares Internacionais, outro evento em Comemoração ao Centenário de Independência no Rio de Janeiro. Porém, há indícios no jornal Correio do Povo (04/10/1922) de que ele, representante do tiro, venceu com 483 pontos a prova individual de pistola em 50 metros nos Jogos Latino-Americanos, deixando o também brasileiro Afrânio Costa (que também esteve presente nos Jogos da Antuérpia) com 472 pontos, na segunda colocação ${ }^{5}$. Na prova de "revólver de guerra", Sebastião Wolf ficou em quarto lugar, com 448 pontos. Esta prova teve como vencedor o brasileiro Guilherme Paranaense, outro que esteve presente em 1920 na Antuérpia, com 508 pontos $^{6}$.

\section{Os eventos comemorativos no Rio Grande do Sul}

Muitos foram os eventos comemorativos realizados no Rio Grande do Sul no ano do Centenário da Independência do Brasil. No interior do Estado, as comemorações artísticas, culturais e religiosas predominaram, enquanto que na capital, Porto Alegre, também ocorreram eventos esportivos. Destacam-se, dentre os acontecimentos esportivos, os Jogos Olímpicos promovidos pela Turnerbund (atual SOGIPA), no local da sua sede, até hoje localizada no Bairro São João de Porto Alegre ${ }^{7}$.

3 As fontes apresentam diferença na marca do arremesso de Willy, como o jornal Correio do Povo (04/10/1922) que informa a medida de 56,645 metros.

$4 \quad$ Essa altura foi a mesma atingida por Ernesto Goycolea, atleta chileno, que manifestou ter dúvidas sobre a correta colocação de Fick, se terceiro ou quarto lugar. A prova foi vencida pelo uruguaio José Amejeiras, com a marca de 3,40 metros, ficando com a segunda colocação, Ernesto Kausel do Chile.

${ }_{6}^{5}$ Na terceira colocação ficou o argentino Comginus, com 418 pontos.

${ }^{6}$ Em segundo lugar ficou o Tenente Ferraz, com a pontuação de 490; mesma pontuação do terceiro lugar, o argentino Comginus.

${ }^{7}$ Esse mesmo espaço já foi um conglomerado de chácaras que se alinhavam ao caminho do Passo d'Areia (atual Avenida Benjamin Constant), e era habitado por ilhéus e seus descendestes vindos dos Açores em Portugal, imigrantes alemães e principalmente italianos.

Pensar a Prática, Goiânia, v. 17, n. 2, p. 485-502, jan./mar. 2014 492 
Os Jogos Olímpicos foram organizados por uma comissão ${ }^{8}$ e contaram com a participação dos seguintes clubes: Clube de Regatas Almirante Barroso; Associação Cristã de Moços; Foot Ball Club Porto Alegre; Esporte Clube São José, Grêmio Foot Ball Porto Alegrense; Sport Club Internacional; Grêmio Náutico União; Clube de Regatas Vasco da Gama; Club de Regatas Guahyba; Canottieri Duca degli Abbuzzi; Turnerbund, Sport Club Tiradentes; e Club Cyclista Rio Grandense.

Além dos clubes, a Brigada Militar também enviou atletas para participar das competições. Houve a participação de 142 atletas nas competições de corrida, arremesso e lançamentos ${ }^{9}$, evidenciando-se que os jogos privilegiaram modalidades do Atletismo.

Os Jogos Olímpicos, que duraram dois dias, se encerraram no final do dia oito de Setembro com a divulgação da classificação dos clubes: $1^{\circ}$ ) Clube de Regatas Almirante Barroso (sete medalhas de ouro e duas de prata); $2^{\circ}$ ) Turnerbund (duas de ouro, duas de prata e cinco de bronze); $3^{\circ}$ ) Canottieri Ducca degli Abruzzi (uma medalha de ouro, duas de prata e cinco de bronze); $4^{\circ}$ ) Club de Regatas Guahyba (uma medalha de ouro, uma de prata e duas de bronze; $5^{\circ}$ ) Grêmio Foot Ball Porto Alegrense (uma medalha de ouro e uma de prata); $6^{\circ}$ ) Brigada Militar (duas medalhas de bronze); $7^{\circ}$ ) Grêmio Náutico União (uma medalha de bronze).

Os atletas vencedores receberam medalhas de ouro, prata e bronze e o clube vencedor da corrida de estafetas - que se assemelha com uma de revezamento - recebeu um troféu, sendo esta premiação oferecida pelo Governo do Estado. Os jornais Correio do Povo e A Federação noticiavam no dia 12 de Setembro: uma multidão incalculável assistiu as provas e viu o Clube Almirante Barroso levantar a taça, fazendo uma linda festa com bandeiras e cartazes, mesmo não sendo superado nenhum recorde estadual.

Percebe-se que a ideia de "Jogos Olímpicos" naquela época em Porto Alegre estava associada às provas/modalidades do Atletismo. Além disso, a premiação também seguia o modelo dos Jogos Olímpicos do COI, por meio de classificação dos clubes em razão do número de medalhas de ouro, prata e bronze.

\footnotetext{
${ }^{8}$ Composta pelos senhores Henrique Huber, Willy Klohs, tenente Napoleão A. Guimarães e médico Rodolfo Campani.

${ }^{9}$ Corrida $100 \mathrm{~m}$ rasos (42 atletas inscritos), corrida 400m (40 atletas), corrida 1500m (39 atletas), salto em distância (33 atletas), corrida de $100 \mathrm{~m}$ com obstáculos (27 atletas), arremesso de peso (21 atletas), lançamento de disco (12 atletas), lançamento de dardo (12 atletas), corrida de estafetas em 1600m (11 equipes participantes). Em razão do número de inscritos, na maioria das provas houve a etapa eliminatória no dia sete de Setembro, com exceção da corrida de 1500 metros, realizada no dia oito de Setembro.
}

Pensar a Prática, Goiânia, v. 17, n. 2, p. 485-502, jan./mar. 2014 493 
Enquanto no Rio Grande do Sul, as comemorações do Centenário da Independência alcançavam o interior. Um exemplo desse processo é a cidade de Estrela, onde, como descreve Kilpp (2012), o Centenário da Independência recebeu grande destaque nas páginas do jornal local, "O Paladino". A mesma autora relata que, desde a metade do ano de 1922, o jornal já anunciava para a população "preparar-se" para tais festejos.

Entre esses preparativos, podemos mencionar a distribuição do "hino da independência" realizada pela prefeitura a cada escola municipal. Quanto à forma entusiasmada que o periódico relatava as representações de patriotismo demonstradas pela população da cidade, cabe apontar que se trata de um jornal autodenominado "Folha Republicana", o que pode ter influenciado na descrição mais exaltada das comemorações como meio de expor o patriotismo desta cidade para todo o Estado.

Outros municípios do interior do Estado registraram eventos para o dia sete de Setembro: na cidade de Livramento, distribuição de esmolas; em Bagé, missa e apresentação de bandas; exposições artísticas foram realizadas em Pelotas; em Jaguarão, cavalhada e distribuição de carne aos pobres; e a cidade de Sapucaia ofereceu um churrasco e muito chopp para a população que compareceu no ato comemorativo - destaques apontados pelo jornal A Federação (24/09/1922).

Além disso, como relata o jornal Correio do Povo (05/08/1922), vários municípios inauguraram monumentos em homenagem ao Centenário da Independência do Brasil. Dentre eles, podemos mencionar os obeliscos em São Gabriel, Jaguari e Erechim, além do Monumento Niederauer em Santa Maria, e os localizados na Praça da Bandeira de Santa Cruz do Sul.

Em Porto Alegre, as competições esportivas eram em grande número e em diferentes práticas. A competição "Taça Centenário da Independência do Brasil" também fez parte das comemorações, sendo disputada por clubes filiados à Federação Rio Grandense de Desportos e sob a direção da Associação Porto Alegrense de Foot Ball. Disputada entre os dias 6 e 8 de Setembro de 1922, na capital sul-rio-grandense, especificamente, no campo do Tunerbund, envolveu quatro clubes da Capital e do interior: Sport Club Rio Grande, Grêmio Foot-Ball Porto Alegrense, Sport Club Ruy Barbosa e Riograndense de Santa Maria, segundo o jornal Correio do Povo (10/09/1922). A final foi realizada no dia 8 de Setembro, no campo do Moinhos de Vento. O Rio Grande venceu o Grêmio com facilidade pelo placar de 4 x 1 .

Outro evento futebolístico, realizado para comemorar as mesmas festividades, foi a Taça Independência. Este evento consistiu em um campeonato de futebol, efetivado no dia 8 de Setembro na Chácara dos Eucalyptus, envolvendo as seguintes equipes: Sport Club Cruzeiro, Sport Club 
São José e Sport Club Internacional, todos esses da capital do Estado, além dos do interior: Brasil de Pelotas e Rio Grandense de Rio Grande. Na manchete do jornal Correio do Povo (10/09/1922), destaque para a equipe do Internacional que sagrou-se campeã.

Assim como o futebol, a prática do turfe também marcou presença entre os eventos comemorativos do Centenário da Independência, em Porto Alegre, com o Grande Prêmio 7 de Setembro. Como o jornal A Federação (14/09/1922) traz em suas páginas, este prêmio aconteceu no próprio dia 7 de Setembro, e teve como vencedores os filhos do criador Hall Cross, conhecido pelo seu haras intitulado Rio-Grandense. No cenário esportivo do remo, um evento comemorativo foi realizado, segundo Castello (1923), a Regata do Centenário da Independência $(1822$ - 1922) foi vencida pelo Grêmio de Regatas Almirante Tamandaré.

$\mathrm{O} 7^{\circ}$ Batalhão de Caçadores também participou das comemorações do Centenário com provas atléticas. Existem dúvidas quanto ao dia exato da realização deste evento, como aponta o jornal Correio do Povo (12/09/1922), se ele ocorreu no dia oito ou nove de Setembro, ou, ainda, se foi realizado durante os dois dias, como menciona o jornal A Federação (14/09/1922). A disputa foi entre as companhias. Cada companhia poderia inscrever no máximo dois atletas por prova individual, a saber: corrida de 100 metros, corrida de mil metros, salto em largura, futebol, luta de tração à corda, arremesso de granada, corrida de estafetas com obstáculos, salto em altura e esgrima. As provas foram realizadas no campo da Redenção (atual Parque Farroupilha), com exceção dos jogos de futebol, que foram disputados no campo do Sport Club Cruzeiro.

O jornal Correio do Povo (10/09/1922) relata que ainda houve clubes que optaram por eventos particulares, com suas próprias comemorações ao Centenário de Independência, como o Grêmio Gaucho, que organizou o hasteamento das bandeiras, além de promover passeatas e sessão cívica. Neste mesmo caminho, o jornal a Federação (14/09/1922) destaca que a Sociedade de Tiro Porto Alegrense elaborou uma revista em comemoração ao Centenário de Independência e o Clube de Regatas Almirante Barroso organizou um torneio de bolão em homenagem à data.

Além da tradição em promover eventos, o estado do Rio Grande do Sul quase sempre marcou presença em competições nacionais e internacionais. Essa característica pode ser novamente evidenciada no ano de 1922, quando atletas do Estado foram ao Rio de Janeiro participar dos Jogos Latino-Americanos.

Pensar a Prática, Goiânia, v. 17, n. 2, p. 485-502, jan./mar. 2014 495 


\section{Considerações Finais}

As comemorações do Centenário da Independência do Brasil (18221922) foram marcantes para a construção de representações da identidade cultural brasileira, por meio da utilização de fragmentos da memória cultural do país, onde os esportes também serviram como revitalizadores desta memória. Para tanto, houve vários desdobramentos que integravam a programação, dentre esses, os Jogos Olímpicos na capital do Rio Grande do Sul, Porto Alegre.

Além do Rio Grande do Sul, outras capitais brasileiras promoveram eventos esportivos comemorativos ao Centenário, como foi o caso dos Jogos Latino-Americanos na capital do país na época, o Rio de Janeiro. Neste evento, os atletas porto-alegrenses tiveram uma participação significativa nas competições esportivas. Tal participação provavelmente resultou da forte tradição dos sul-rio-grandenses no campo do associativismo esportivo.

Embora os Jogos Latino-Americanos tenham reunido expressiva audiência, não foi cogitado como evento de porte. Possivelmente, a invisibilidade na memória do esporte brasileiro deste pressuposto megaevento, considerando o tamanho e não o impacto naquela época, se deve ao fato de a organização ter sido feita à sombra dos festejos do Primeiro Centenário da Independência. Desta forma, enfatiza-se a importância de preservar a memória esportiva brasileira, desvendando eventos e atletas que muitas vezes acabam esquecidos ou até são desconhecidos. Talvez este fosse o caso dos Jogos Olímpicos realizados em Porto Alegre no ano de 1922.

Estes Jogos Olímpicos tiveram a participação de diversos clubes esportivos, como também da Brigada Militar, que historicamente tem uma tradição na promoção da prática esportiva no Estado. Outras competições esportivas contemplaram várias modalidades, desde o remo, o futebol, a natação, o ciclismo, o atletismo, até o turfe. Algumas dessas práticas eram promovidas pelas associações esportivas porto-alegrenses desde a segunda metade do século XIX, quando foram instituídas.

Em Porto Alegre, atletas sul-rio-grandenses também se destacaram no Campeonato Nacional, que selecionou os três melhores de cada prova para representar o Brasil nos Jogos Latino-Americanos. Dos sete sul-riograndenses que foram disputar o Campeonato Nacional, seis foram selecionados para compor a equipe brasileira. Quanto ao desempenho dos sul-riograndenses nos jogos, podemos destacar a grande vitória de Willy Seewald, que superou o recorde sul-americano, e Willy Fick, atleta do salto com vara, que suplantou seu próprio recorde brasileiro na competição. Willy Seewald, dois anos depois, representou o Brasil nos Jogos Olímpicos realizados em Paris, no ano de 1924.

Pensar a Prática, Goiânia, v. 17, n. 2, p. 485-502, jan./mar. 2014 496 
Certamente o aspecto mais relevante dos Jogos Latino-Americanos foi a mobilização inédita que os mesmos possibilitaram ao esporte regional, fazendo com que todos os envolvidos questionassem a modalidade que desejavam desenvolver e como seriam capazes de construir e de alcançar seus objetivos, numa época em que a América Latina já não desejava mais somente aceitar as conquistas esportivas dos europeus. Os Jogos LatinoAmericanos foram uma das competições regionais que vieram a dar forma aos Jogos Pan-Americanos, que acabou unificando essas competições em 1951, com a realização dos Jogos Pan-Americanos de Buenos Aires.

\title{
SPORTING EVENTS IN CELEBRATION OF THE CENTENARY OF THE INDEPENDENCE OF BRAZIL (1822-1922) IN RIO GRANDE DO SUL
}

\begin{abstract}
In 1922 Brazil celebrated its independence centenarian, This year was marked by lots of festivities in many areas. One of these events was the Latin-American Games hosted by Rio de Janeiro. Porto Alegre also promoted his sportive event, the Olympic Games. This research aims to describe how the Olympic Games succeed in Porto Alegre. Data extraction were conducted in printed sources, especially newspapers. The data analysis revealed sport's recognition as a cultural practice present in both festivities. Porto Alegre had an important participation in the commemorations by sending athletes to Rio de Janeiro's Games and promoting a sportive competition called Olympic Games. This participation probably resulted from Porto Alegre's strong tradition in sports association.
\end{abstract}

Keywords: Sports History. Latin-american Games. Olympic Games.

\section{EVENTOS DEPORTIVOS EN CELEBRACIÓN DEL CENTENARIO DE LA INDEPENDENCIA DE BRASIL (1822-1922) EN RIO GRANDE DO SUL}

\section{Resumen}

En 1922, Brasil conmemoró el centenario de su independencia, un año marcado por diversas celebraciones Entre los eventos estaban los Juegos de América Latina, organizados en Río de Janeiro. Porto Alegre también promovió su evento deportivo, los Juegos Olímpicos. El objetivo de esta investigación es reconstruir como sucedió los Juegos Olímpicos en Porto Alegre. Para eso, fueron analizados materiales impresos, sobre todo periódicos. El análisis reveló el reconocimiento del deporte como una práctica cultural privilegiada en estas celebraciones. Porto Alegre tuvo participación destacada a través del envió de deportistas a los Juegos de Río de Janeiro así como organizando un evento. Tal participación, resulta probablemente de su fuerte tradición en asociaciones deportivas.

Pensar a Prática, Goiânia, v. 17, n. 2, p. 485-502, jan./mar. 2014 497 
Palabras-claves: Historia del Deporte. Juegos Latino-americanos. Juegos Olímpicos.

\section{Referências}

ASSMANN, J. Collective Memory and Cultural Identity. New German Critique, n. 65, Cultural History/Cultural Studies. Spring - Summer, p. 125$133,1995$.

BRASIL. Estatutos da Confederação Brasileira de Desportes. Diário Official, 26 de julho de 1922.

BURKE, P. A história como memória social. In: BURKE, Peter. O mundo como teatro. Estudos de antropologia histórica. Lisboa: Difel, 1992.

CASTELLO, J. Álbum commemorativo ao $20^{\circ}$ aniversário do Gremio de Regatas Almirante Tamandaré 1903-1923. Porto Alegre: Edição Revista Vida Gaúcha, 1923.

CHARTIER, R. A história hoje: dúvidas, desafios, propostas. Revista Estudos Históricos, Rio de Janeiro, v. 7, n. 13, p. 97-113, 1994.

COMEMORAÇÕES do Centenário. Correio do Povo, Porto Alegre, p. 7, 5 de outubro, 1922.

COMEMORAÇÕES do Centenário. Correio do Povo. Porto Alegre, p. 2, 10 de Setembro, 1922.

DACOSTA, L.; MIRAGAYA, A. "Estado da arte do conhecimento sobre legados de megaeventos esportivos no exterior e no Brasil- Introdução e temas dos autores do livro 'Legados dos Megaeventos Esportivos". Legados de Megaeventos Esportivos. Brasília: Shape, 2008.

ESPORTE nos Festejos do Centenário. A Federação. Porto Alegre, p. 4, 14 de Setembro de 1922.

FERREIRA, E. 1923 - Fundação da Federação Brasileira de Tiro. Rio de Janeiro, agosto de 2001. Disponível em: <http://www.tiroflu.com/artigos/eduardo_ferreira/fundacao_da_fed_bras_tir o.htm > Acesso em: 16 de agosto de 2013. 
Hymno da Independencia. O Paladino. Estrela, p. 1, 23 de julho, 1922.

JOGOS Latino-americanos. Correio do Povo, Porto Alegre, p. 5, 3 de Agosto, 1922.

JOGOS Latino-americanos. Correio do Povo, Porto Alegre, p. 8, 28 de Agosto, 1922.

JOGOS Latino-americanos. Correio do Povo, Porto Alegre, p. 8, 6 de Setembro, 1922.

JOGOS Latino-americanos. Correio do Povo, Porto Alegre, p. 8, 7 de Setembro, 1922.

JOGOS Latino-americanos. Correio do Povo. Porto Alegre, p. 8, 4 de Outubro, 1922.

JOGOS Olímpicos. Correio do Povo. Porto Alegre, p. 5, 12 de Setembro, 1922.

JOGOS do Rio. A Federação. Porto Alegre, p. 5, 12 de Agosto, 1922.

JOGOS do Turnerbund. A Federação, Porto Alegre, p. 4, 8 de setembro, 1922.

JOGOS do Rio de Janeiro. A Federação, Porto Alegre, p. 5, 14 de outubro, 1922.

KILLP, C. E. O Turnen e o esporte nas associações teuto-brasileiras de Estrela/Rio Grande do Sul. Dissertação (Mestrado em Ciências do Movimento Humano). Universidade Federal do Rio Grande do Sul (UFRGS), Porto Alegre, 2009.

LARA, S. Os documentos textuais e as fontes do conhecimento histórico. Anos 90. Porto Alegre, v. 15, n. 28, p. 17-39, 2008.

LENK, Maria. Braçadas e Abraços. Rio de Janeiro, RJ: Gráfica Bradesco S.A., 1986.

MARTINS, C. A década de 20. Revista Movimento, Porto Alegre, 1994. Disponível em: 
<http://www.celpcyro.org.br/v4/Estante_Autor/decada_20_integra.htm> Acesso em: 16 de agosto de 2013.

MAZO, J. Z. Banco de dados das associações esportivas e de Educação Física de Porto Alegre/Rio Grande do Sul (1867-1945). Livro Digital. Novo Hamburgo, RS: Editora da Feevale, 2010.

MAZO, J. Z.; MADURO, P.; PEREIRA, E. A prática do atletismo nas associações desportivas da cidade de Porto Alegre/Rio Grande do Sul nas primeiras décadas do século XX: Primeiros Indícios. Revista Arquivos em Movimentos. Rio de Janeiro, v. 6, n. 2, p. 42-56, 2010.

MAZO, J.; FROSI, T.; MADURO, P. O atleta olímpico brasileiro Willy Seewald: memórias do primeiro recordista nacional de lançamento de dardo. Revista Brasileira de Ciências do Esporte, v. 34, p. 537-555, 2012.

MAZO, J. Z.; ASSMAN, A. B.; DIAS. C.; SILVA. C. F.; BALBINOTTI. C. A.; KILLP, C. E.; CARMONA, E. K.; PEREIRA, E. L.; PICCOLI, J. C.; MADURO, P. A.; VICARI, P. R.; MORAES, R. D.; MARTINI, S. B.; FROSI, T. O.; LYRA, V. B. Associações Esportivas no Rio Grande do Sul: lugares e memórias. Livro Digital. Novo Hamburgo, RS: Editora Feevale, 2012.

MOTTA, M. A Nação Faz Cem Anos: A Questão Nacional no Cenário da Independência. Rio de Janeiro: Ed. FGV-CPDOC, 1992.

MORAES, H. Jogadas Insólitas: Amadorismo e Processo de Profissionalização no Futebol Carioca (1922-1924). 2009. Dissertação de Mestrado Programa de Pós-Graduação em História Social, UERJ, Rio de Janeiro, 2009.

OS Jogos olímpicos do centenário. Correio do Povo. Porto Alegre, p. 2, 3 de Setembro, 1922.

OS Festejos Sportivos do Centenário. A Federação. Porto Alegre, p. 2, 24 de Setembro, 1922.

PADILHA, G. A Natação em Porto Alegre: Do Rio Guaíba às Piscinas dos Clubes. Trabalho de Conclusão de Curso. Universidade Federal do Rio Grande do Sul/ Escola de Educação Física. Porto Alegre, 2012 apud AMA-

Pensar a Prática, Goiânia, v. 17, n. 2, p. 485-502, jan./mar. 2014 500 
RO JÚNIOR, J. (Org.). Almanaque Esportivo do Rio Grande do Sul. $1^{\circ}$ Ano. Porto Alegre: Tipografia Esperança, 1942.

PINSKI, C. Fontes históricas. São Paulo: Contexto, 2005.

SANTOS, J. Revolução Vascaína: a profissionalização do futebol e inserção sócio-econômica de negros e portugueses na cidade do Rio de Janeiro (1915-1934). 2010. Tese Doutorado - Faculdade de Filosofia, Letras e Ciências Humanas, Universidade de São Paulo. São Paulo, 2010.

SCHEMES, C. Festas Cívicas e Esportivas: Um estudo comparativo dos governos Vargas (1937-1945) e Perón (1946-1955). Novo Hamburgo: Feevale, 2005.

SILVA, H. "Rememoração/comemoração: as utilizações sociais da memória". Revista Brasileira de História, São Paulo, v. 22, no 44, p. 425-438, 2002.

SOEIRO, R. A Contribuição Da EsEFEx para o Esporte Nacional (19332000). 2003. Dissertação de Mestrado - Programa de Pós-Graduação em Ciência da Motricidade Humana. Universidade Castelo Branco, Rio de Janeiro, 2003.

SUPLEMENTO Esportivo. O Imparcial, Rio de Janeiro, 16 setembro, 1922.

TENÓRIO, M. "Um Cuauhtémoc carioca: comemorando o Centenário da Independência do Brasil e a raça cósmica". Revista Estudos Históricos. Rio de Janeiro, v. 7, nº 14, p. 123-148, 1994.

TORRES. C. The Latin American 'Olympic Explosion' of the 1920s: Causes and Consequences. The International Journal of the History of Sport. v. 3, n 7, 2006.

Jogos Olímpicos Latino-Americanos de 1922 - Rio de Janeiro. In: DACOSTA, L. Atlas do Esporte no Brasil. Rio de Janeiro: Shape, 2005, p. 812-813.

Jogos Olímpicos Latino-Americanos - Rio de Janeiro 1922. CBAt. Manaus, 2012.

Pensar a Prática, Goiânia, v. 17, n. 2, p. 485-502, jan./mar. 2014 501 
Recebido em: 17/08/2013

Revisado em: 15/10/2013

Aprovado em: 26/11/2013

Endereço para correspondência:

paulorenvicari@ hotmail.com

Paulo Renato Vicari

Universidade Federal do Rio Grande do Sul

Av. Paulo Gama, 110 - Bairro Farroupilha - Porto Alegre - Rio Grande do Sul CEP: 90040-060 - Fone: +55 5133086000 